\title{
CLASSIFICAÇÃO DE ROTAS DE ACESSO NO CAMPUS DA UNICAP
}

\author{
SILVA, Jhullianny Kese Sousa (1); \\ BAPTISTA, Arthur Henrique Neves (2)
}

(1) Universidade Católica de Pernambuco, Graduanda em Arquitetura e Urbanismo e-mail:jhully jk12@hotmail.com

(2) Universidade Católica de Pernambuco, Doutor em Desenvolvimento Urbanos e-mail:arthurbap@gmail.com

\begin{abstract}
RESUMO
Este trabalho trata de uma análise segundo os procedimentos metodológicos da Teoria da Acessibilidade Efetiva com planos de verificação para estruturas de circulação de pedestres no campus da Universidade Católica de Pernambuco. O propósito é relacionar a pessoa, a tarefa, o ambiente e o contexto, para avaliar a acessibilidade do campus com critérios ergonômicos. Os resultados podem contribuir em futuras propostas para o aprimoramento de rotas acessíveis visando um Desenho Universal.
\end{abstract}

Palavras-chave: Acessibilidade Efetiva, Ergonomia, Desenho Universal.

\begin{abstract}
This work is an analysis according to the methodological procedures of the Theory of Effective Accessibility with verification plans for pedestrian circulation structures on the campus of Universidade Católica de Pernambuco. The purpose is to relate the person, the task, the environment and the context, to evaluate the accessibility of the campus with ergonomic criteria. The results can contribute to future proposals for the improvement of accessible routes for a Universal Design.
\end{abstract}

Keywords: Effective Accessibility, Ergonomic, Universal Design.

\section{INTRODUÇÃO}

O artigo se refere à Teoria da Acessibilidade Efetiva (TAE), realizando estudos de rotas internas do campus da Universidade Católica de Pernambuco, localizado no bairro de Santo Amaro, Recife-PE. A UNICAP por sua posição estratégica no centro da cidade conecta vias - como a Rua do Príncipe e Rua Almeida Cunha - que possuem um grande fluxo de pedestres, tanto de estudantes quanto de pessoas que utilizam o campus para passagem.

\section{CONCEITUAÇÃO TEÓRICA}

No cotidiano se torna dificultoso se deslocar na cidade, com os obstáculos, barreiras arquitetônicas e urbanísticas. Devemos estar cientes que cada indivíduo possui necessidades distintas - como deficiências ou mobilidade reduzida - e proporcionar 


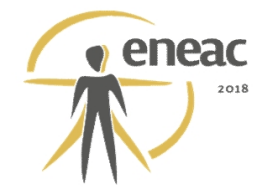

acessibilidade para que todos tenham os mesmos direitos irá proporcionar que esses indivíduos possam acessar qualquer local e desenvolver atividades (PINHEIRO, 2006).

A TAE é um sistema que reúne relações, proposições, modelos e procedimentos metodológicos que visam aferir, descrever, explicar e predizer a experiência efetiva da acessibilidade. Sendo a acessibilidade efetiva uma experiência vivenciada por um sistema Acessante (pessoa), que executará ações de uma tarefa, em um dado contexto em um sistema Acessado (ambiente). A teoria contribui com soluções universais em relação a acessibilidade que considerem as interações entre pessoas, ambiente, atividades e contextos (BAPTISTA, 2010).

A Teoria da Acessibilidade é conceitualmente baseada na Ergonomia que objetiva modificar os sistemas de trabalho para adequar a atividade nele existente, às características, habilidades e limitações das pessoas com vistas ao seu desempenho eficiente, confortável e seguro (ABERGO, 2000), na filosofia do Desenho Universal que visa atender uma ampla gama da população (CAMBIAGHI, 2013) e na Classificação Internacional de Funcionalidade (CIF) da Organização Mundial de Saúde.

\section{PROCEDIMENTOS METODOLÓGICOS}

Nesta etapa da pesquisa, o levantamento foi realizado a partir de uma breve apreciação, conforme a percepção subjetiva do pesquisador. Com base dos critérios da TAE e da configuração do Sistema Acessante - Tarefa - Acessado (SATA), foram utilizados:

- Três tipos de Sistema Acessante: [1] uma pessoa jovem sem deficiências aparentes, que serve como grupo de controle para comparar com os demais. [2] uma pessoa com deficiência física usuária de cadeira de rodas, contemplando um caso severo de limitação física. [3] uma pessoa com deficiência visual total, contemplando um caso severo de limitação sensorial.

- Dois tipos de Tarefa: [1] Contexto Positivo - o usuário está caminhando com tranquilidade e num dia/horário considerando calmo. [2] Contexto Negativo - o usuário está caminhando num ritmo acelerado para suas condições e num dia/horário considerado tumultuado.

- Oito rotas definidas como Sistemas Acessados.

Na tabela 01, as cores representam o nível de Acessibilidade Efetiva adquiridos e cada um dos sistemas acessados analisados (BAPTISTA, 2010).

Tabela 01: Convenção de cores para representação do nível de Acessibilidade Efetiva

\begin{tabular}{|c|c|c|c|c|c|c|c|}
\hline $\begin{array}{c}\text { Faixas do } \\
\text { Espectro de } \\
\text { Acessibilidade }\end{array}$ & $\begin{array}{l}\text { Ultra- } \\
\text { violeta }\end{array}$ & Azul & Verde & Amarela & Laranja & Vermelha & $\begin{array}{c}\text { Infra- } \\
\text { vermelha } \\
\ldots . . . . .\end{array}$ \\
\hline $\begin{array}{l}\text { Acessibilidade } \\
\text { Efetiva }(x)\end{array}$ & $x>1,00$ & $0,80<x \leq 1,00$ & $0,60<x \leq 0,80$ & $0,40<x \leq 0,60$ & $0,20<x \leq 0,40$ & $0<x \leq 0,20$ & $x \leq 0$ \\
\hline & Acesso & \multicolumn{5}{|c|}{ Acesso possivel - intermediário } & \multirow{3}{*}{$\begin{array}{c}\text { Acesso } \\
\text { nulo }\end{array}$} \\
\hline Segurança & pleno com & Adequada & Boa & Razoável & Pouca & Sem & \\
\hline Conforto & excessos & Adequado & Bom & Razoável & Pouco & Sem & \\
\hline
\end{tabular}

Fonte: (BAPTISTA, 2010) 


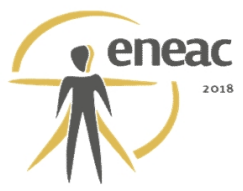

\section{ANÁLISE E CONSIDERAÇÕES}

Com base na TAE, sob um olhar ergonômico e visando um Desenho Universal, conclui-se que $\mathrm{o}$ ambiente oferece distintos níveis de Acessibilidade Efetiva para cada usuário. $\mathrm{O}$ sistema acessante $01 \mathrm{sem}$ restrições físicas e sensoriais possui bons níveis tanto no contexto positivo ou negativo. Diferente do sistema acessante 02 e 03, com deficiências físicas e visuais, respectivamente, possuem dificuldades maiores de deslocamento, por motivos diferentes. O próximo passo será um aprofundamento maior da pesquisa, tornando a obtenção dos dados mais sistemática e objetiva, refinando os resultados (Ver figura 04).

Figura 04: Resultados das análises das rotas da UNICAP

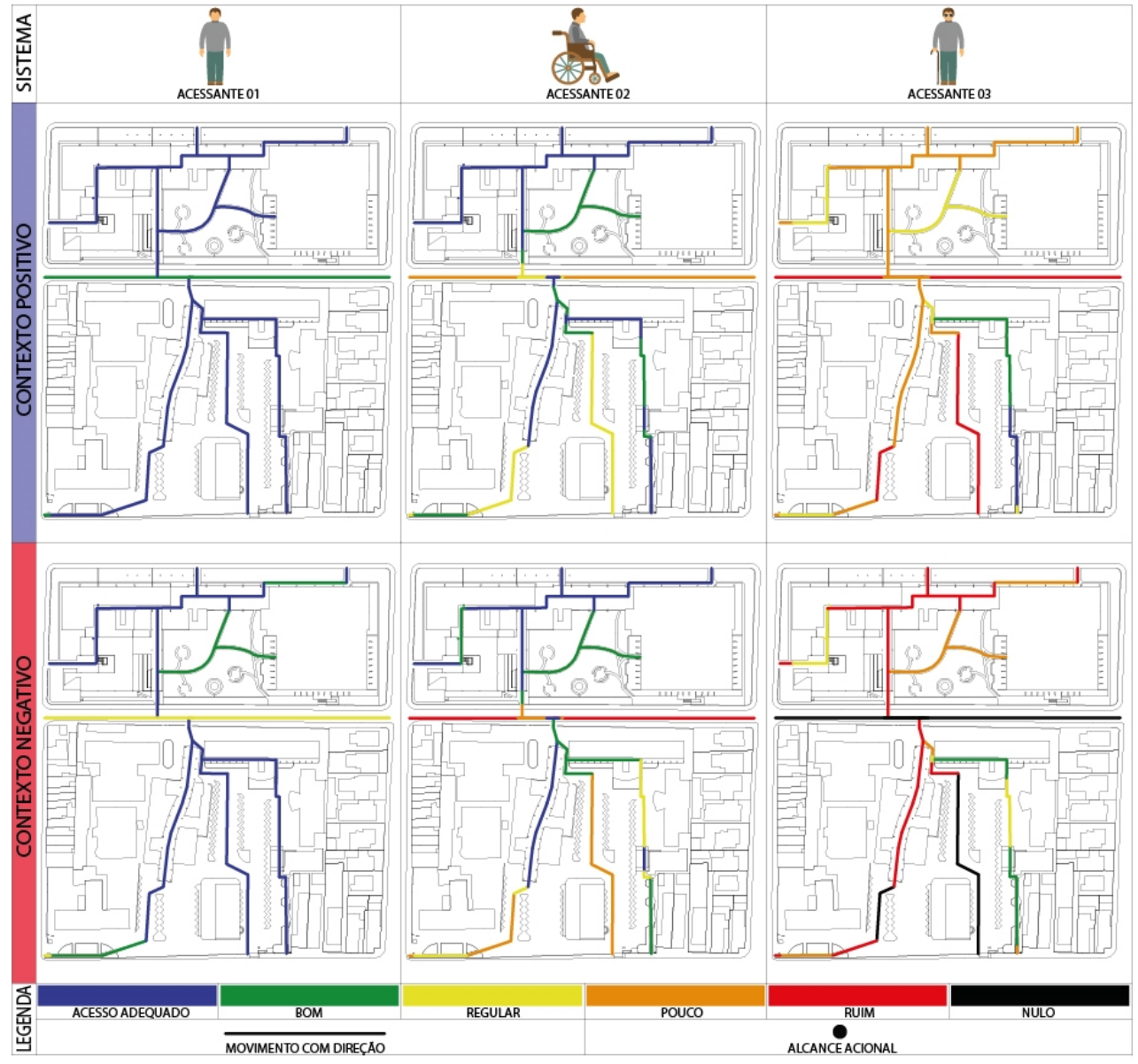

Fonte: Autores (2018)

\section{REFERÊNCIAS BIBLIOGRÁFICAS}

ABERGO - Fundação Brasileira de Ergonomia. A certificação do ergonomista brasileiro. Editorial do Boletim 1/2000, Associação Brasileira de Ergonomia.

BAPTISTA, A. H. N. Proposição da Teoria da Acessibilidade Efetiva com plano de verificação para estruturas de circulação de pedestre. Tese (Doutorado em Desenvolvimento Urbano). Universidade Federal de Pernambuco, Recife: o autor, 2010.

CAMBIAGHI, S. Desenho Universal. Métodos e Técnicas para Arquitetos e Urbanistas. 3 ed. São Paulo: Senac, 2013.

PINHEIRO, Flávia. Guia de acessibilidade em edificações. Belo Horizontes: Crea-MG, 2006. 